Physical preparation of the football player with an intramuscular hamstring tendon tear: clinical perspective with video demonstrations

\author{
Matt Taberner, ${ }^{1}$ Daniel Dylan Cohen ${ }^{2}$
}

\section{CASE SCENARIO}

Hamstring strain injuries (HSIs) are common injuries in professional sport and the musculotendinous junction the most frequently injured site. ${ }^{1}{ }^{2}$ MRI proves that the tendon extends into the muscle belly and has increased awareness of the intramuscular tendon injury. ${ }^{3}$ Some argue that this subtype of HSI may require surgical repair. Currently, there is no consensus on intramuscular tendon injury management; there is agreement that players are at an increased risk of re-injury on return to play (RTP). ${ }^{3}$ Evidence suggests that clinical decision-making, based on achieving functional goals, is an essential element of successful rehabilitation. ${ }^{4}$

In this video-supported education review with a strong clinical slant, I outline the rehabilitation of an English Premier League footballer who suffered a proximal hamstring intramuscular tendon injury during competition. The conceptual goal was to mechanically load the muscle-tendon unit hoping to improve tensile strength, elastic stiffness and cross-sectional area. Adequate high and maximal speed running exposure and objective neuromuscular performance data informed progression through rehabilitation and RTP. The player returned to competition in 120 days and remained injury free 13 months later.

\section{MECHANICAL LOADING}

During rehabilitation following initial physiotherapy care, isometric hamstring exercises were prescribed, beginning with single-leg heel drives (figure 1), progressing to unloaded, then loaded bilateral isometric hip extension holds (online supplementary video 1),

\section{${ }^{1}$ Performance Department, Everton Football Club, Liverpool \\ ${ }^{2}$ Faculty of Life Sciences, University of Santander (UDES), Bucaramanga, Colombia}

Correspondence to Matt Taberner, Everton Football Club, Liverpool L26 3UE, UK;

matt.taberner@evertonfc.com

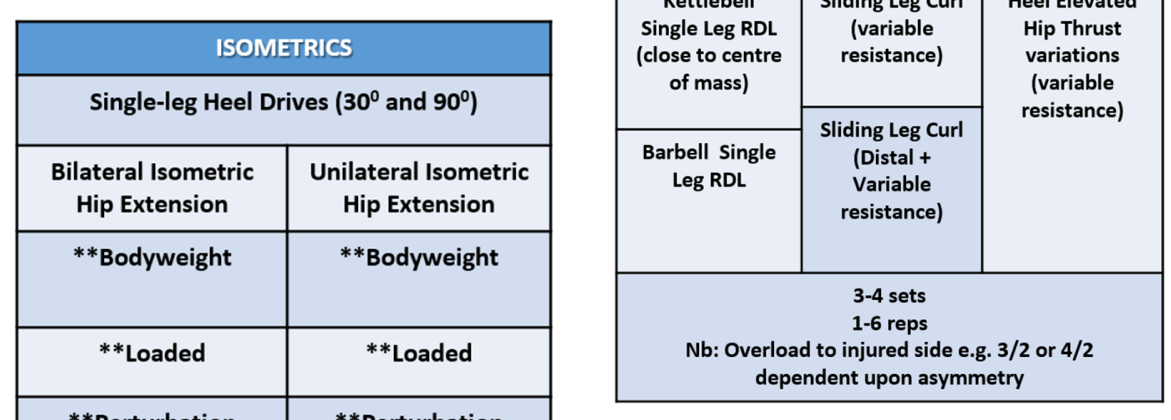

Figure 2 Progression of strength exercises for hamstring-tendon loading.

this programme. A future challenge is to try to study these processes in vivo.

In conjunction with isometric hamstring exercises, dynamic exercises, including bilateral gluteal bridging, were introduced, and full range of motion

\begin{tabular}{|c|c|}
\hline \multicolumn{2}{|c|}{ STRENGTH: Intermuscular emphasis } \\
\hline $\begin{array}{c}\text { Kettlebell Single-leg } \\
\text { RDL }\end{array}$ & Split Squat \\
\hline Barbell Single-leg RDL & Barbell Split Squat \\
\hline $\begin{array}{l}\text { Barbell Single-leg Good } \\
\text { Morning }\end{array}$ & Barbell Reverse Lunge \\
\hline \multirow[t]{3}{*}{$\begin{array}{l}\text { Barbell Single-leg Good } \\
\text { Morning to Box }\end{array}$} & $\begin{array}{l}\text { Barbell Reverse Lunge } \\
\text { to Box }\end{array}$ \\
\hline & $\begin{array}{l}\text { Barbell Split Squat } \\
\text { Jump to Box }\end{array}$ \\
\hline & $\begin{array}{l}\text { Hanging Kettlebell } \\
\text { Split Squat } \\
\text { (imperfect loading) }\end{array}$ \\
\hline $\begin{array}{r}3-4 \\
\text { Early } \\
\text { End } 3 \\
\text { Nb: Overload to injur } \\
\text { dependent up }\end{array}$ & $\begin{array}{l}\text { ts } \\
\text { reps } \\
\text { reps } \\
\text { side e.g. } 3 / 2 \text { or } 4 / 2 \\
\text { n asymmetry }\end{array}$ \\
\hline
\end{tabular}

Figure 3 Progression of strength exercises with intramuscular emphasis for hamstringtendon loading. 


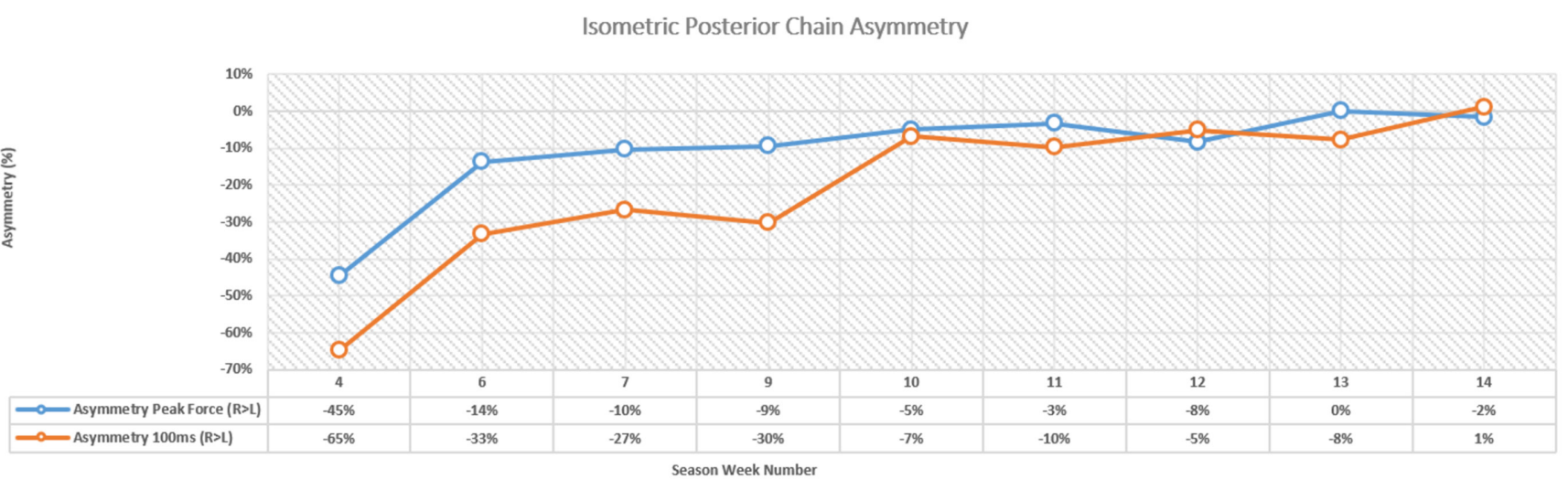

Figure 4 Isometric posterior chain peak force and asymmetry during hamstring-tendon rehabilitation.

unloaded split squats (online supplementary video 4). In my mechanistic model, this would promote collagen synthesis and fibre alignment, and improve tendon tensile strength. Gluteal bridging was progressed in three ways; increasing the lever arm and effective load by elevating the feet, adding load (online supplementary video 5) and selectively overloading the injured limb (online supplementary video 6) to provide a stability challenge alongside increased load. Resistance bands (online supplementary videos 7 and 8 ) were also used to vary the velocity of contraction and reactivity (figure 2 ).

The Romanian deadlift was the principal hip-dominant exercise selected, progressing from bilateral (online supplementary videos 9 and 10) to unilateral (online supplementary video 11), increasing recruitment of the injured muscle group, to target hip extensor strength asymmetry. The reverse lunge (online supplementary video 12) was the principal unilateral knee-dominant exercise selected to develop knee/hip extension strength, with a focus on acceleration mechanics, providing a foundation for more advanced variants (figure 3). Again, we postulate that this would promote

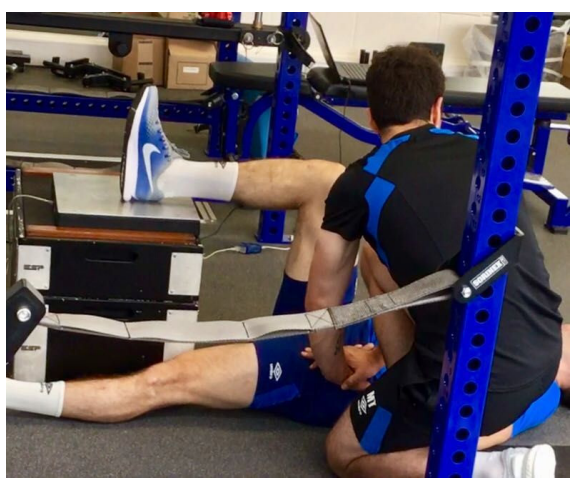

Figure 5 Isometric posterior chain test. intermuscular adaptations specific to the demands of high-speed running (HSR). Exercise progressions focused on increasing intermuscular co-ordination demands, similar to the proximal to distal activation pattern observed during the stance phase of gait, optimising energy transfer from hip to knee and from knee to ankle (online supplementary videos 18, 19 and 20).

\section{Objective criteria for load progression}

At week 7, my criterion for phase; progression peak force (PF) asymmetry $\leq 10 \%$ in a force platform isometric posterior chain (IPC) test ${ }^{5}$ (figures 4 and 5) was achieved, allowing progression of exercise selection to emphasise hip extension

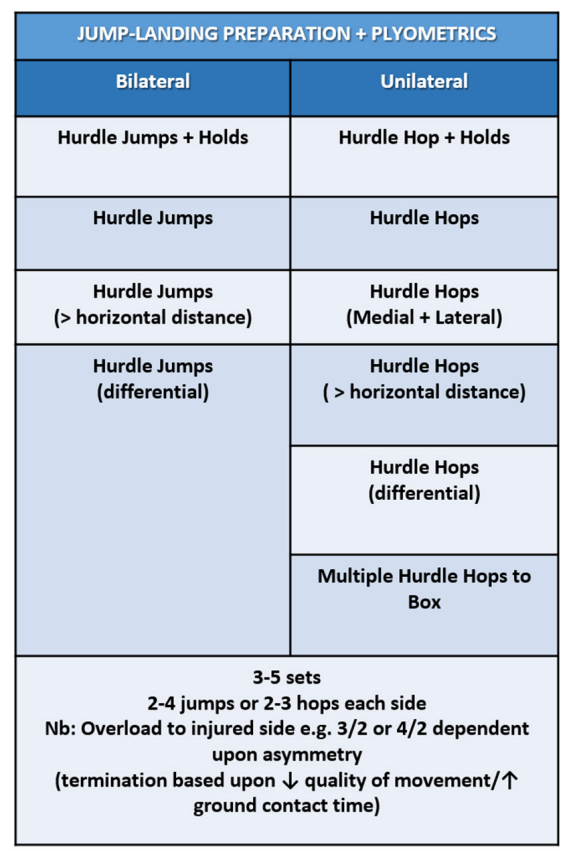

Figure 6 Progression of jump-landing and plyometric exercise for hamstring-tendon loading. and eccentric knee flexion. The eccentric-only sliding leg curl (online supplementary video 13) was introduced, then progressed in volume from $2 \times 4$ reps to $4 \times 5$ reps, followed by the eccentric-concentric version (online supplementary video 14), adding distal load (online supplementary video 15) and resistance bands (online supplementary video 16) to increase speed and strain rate of the eccentric phase, and reactive demands (figure 2).

At week 9, IPC test PF asymmetry was $<10 \%$, my criterion for jumplanding and plyometric activity integration (figure 6), part of a multidimensional approach to enhance lower limb stiffness, neuromuscular control and landing biomechanics, and promote reduced joint loading. During weeks 9-10, jump-landing derivatives were introduced, followed by progression to plyometric activities in weeks 11-14 (figure 6) to target fast stretch shortening activities $(<250 \mathrm{~ms})$ reflecting HSR ground contact times (online supplementary video 21). Achieving $<10 \%$ PF IPC asymmetry was also my criteria for beginning outside preparation. Gradual exposure to high running velocities including $>5.5 \mathrm{~m} \mathrm{~s}^{-1}$ (online supplementary video 22 ) was initiated in week 10 and included periodised exposures to relative HSR early in the week (figure 7). An acute ramp in relative HSR began after IPC test force at $100 \mathrm{~ms}$ (an indicator of rate of force development) asymmetry was $<10 \%$, suggestive of a positive adaptation specific to exposure to the increased load and velocity demands of HSR. Progressive increases in involved limb PF and force at $100 \mathrm{~ms}$ drove reduced asymmetry in these variables, and total $\mathrm{PF}$ reached $300 \mathrm{~N}$ during weeks 13-14 (figure 4 and figure 8). In addition to IPF asymmetry, identified as a risk factor for 


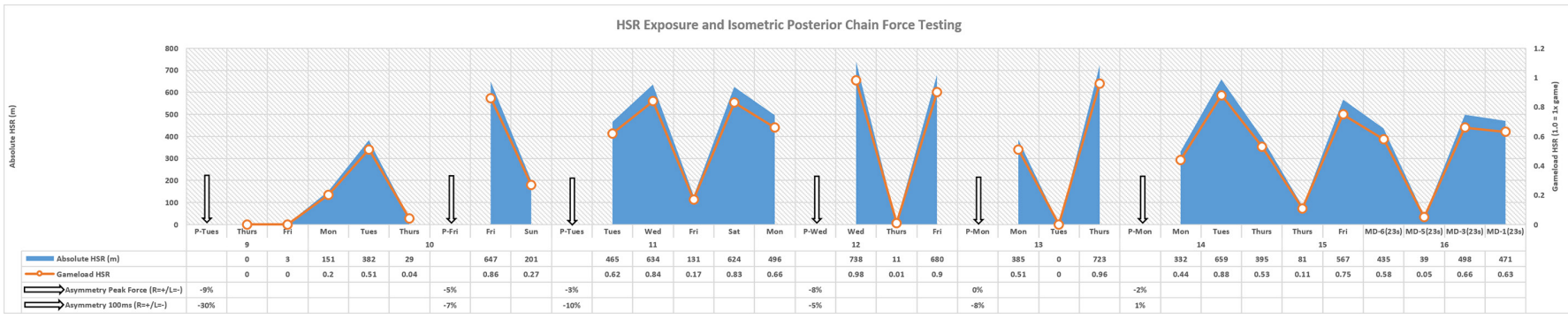

Figure 7 High-speed running (HSR) exposure and isometric posterior chain testing during hamstring-tendon rehabilitation.

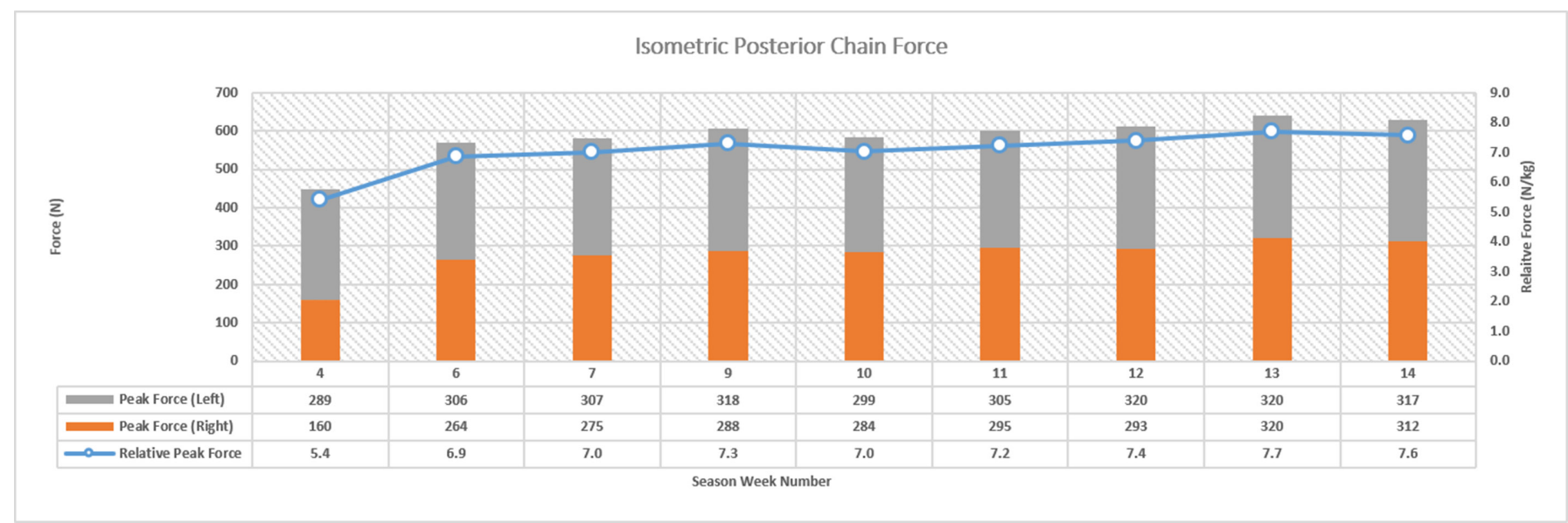

Figure 8 Isometric posterior chain peak force and relative peak force during hamstring-tendon rehabilitation.

HSI recurrence, ${ }^{6}$ prior to RTP eccentric knee flexor strength, assessed using the 'NordBord' (online supplementary video 17) was $500 \mathrm{~N}$ (13\% improvement relative to preseason on the involved side), well above the $350 \mathrm{~N}$ HSI risk threshold, ${ }^{7}$ with asymmetry $<10 \%$ (figure 9).

Acceptable asymmetry was my criterion for exposure to higher cumulative weekly HSR workloads and subsequent progression to loads reflective of relative game load HSR, maximal speeds and positional requirements (online supplementary video 23 ), and to increasingly chaotic running patterns (figure 10. Global positioning systems data were used to ensure gradual return to acute and accumulated weekly HSR distances as large increments can increase re-injury risk, ${ }^{8}$ and adequate exposure to sprints above $90 \%$ maximum velocity (online supplementary video 24), potentially protective against muscle injury. ${ }^{9}$
The player achieved a new maximal speed during the RTP phase (figure 11).

In the 'fast' elite sports environment, decision-making throughout rehabilitation was underpinned by research, clinical evidence and experience. ${ }^{10}$ Progression wasdriven by delivery of specific loading stimuli in both on and off pitch conditioning, assessed with neuromuscular tests quantifying the player's response to load. These data

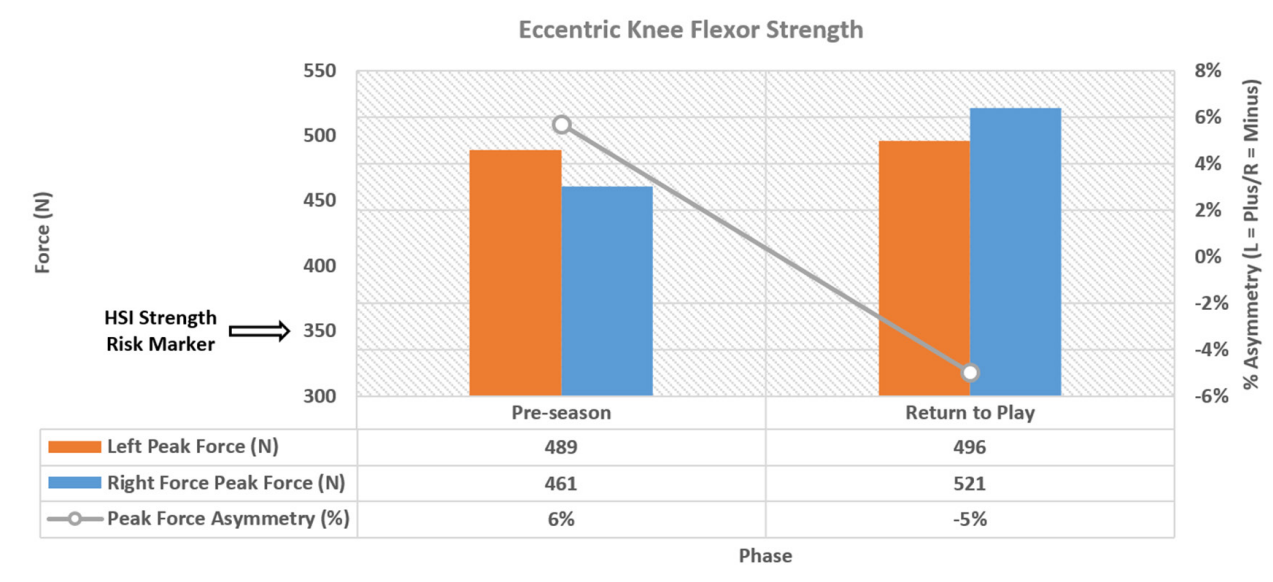

Figure 9 Eccentric peak force and asymmetry testing (NordBord) at baseline (Pre-season) and prior to return to play (RTP). . 


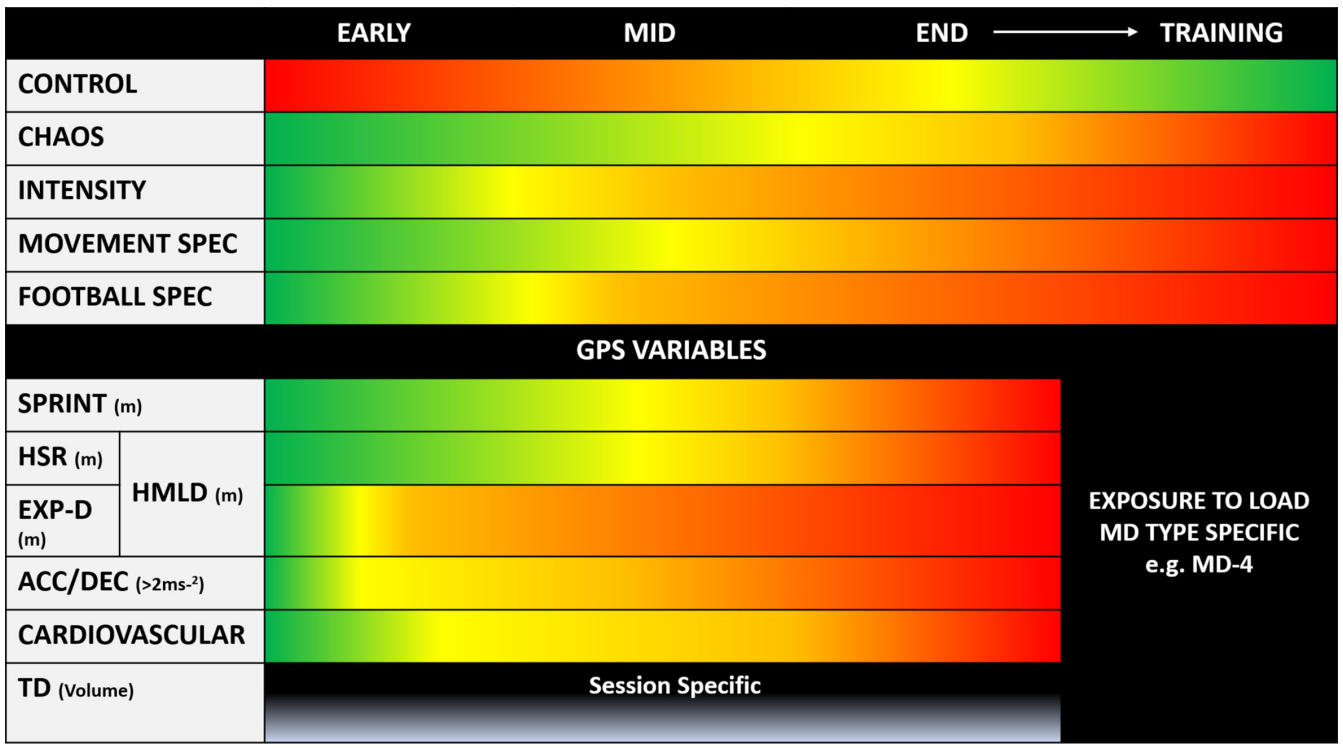

Figure 10 Outdoor physical preparation model for hamstring-tendon rehabilitation. Preparation begins with control moving towards chaos interlinking GPS performance variables (red=high>green=low). GPS (global positioning systems), HSR(high-speed running), EXP-D (explosive distance), HMLD (high metabolic load distance), Acc (accelerations), Dec (decelerations), TD (total distance), MD (match day)

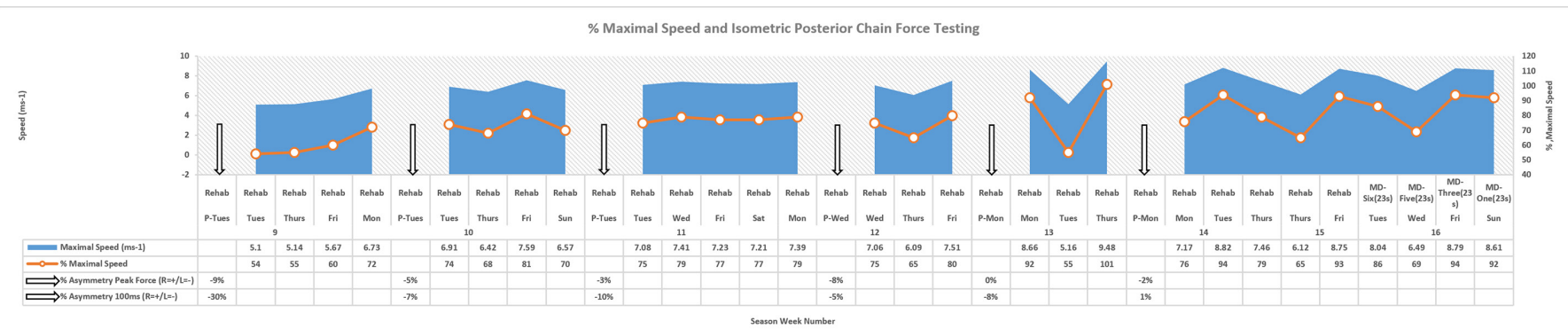

Figure 11 Percentage of relative maximal speed and isometric posterior asymmetry testing during hamstring-tendon rehabilitation.

then informed decisions to facilitate a successful outcome, blending art and science.

Contributors MT led the rehabilitation and planned and wrote the manuscript. DDC provided guidance and assisted in the writing of the manuscript.

Funding This research received no specific grant from any funding agency in the public, commercial or notfor-profit sectors.

Competing interests $D C$ is a co-founder and shareholder in a company that makes force platforms and force platform software.

Patient consent Obtained.

Provenance and peer review Not commissioned; externally peer reviewed.

\section{(6) \\ OPEN ACCESS}

Open access This is an open access article distributed in accordance with the Creative Commons Attribution Non Commercial (CC BY-NC 4.0) license, which permits others to distribute, remix, adapt, build upon this work non-commercially, and license their derivative works on different terms, provided the original work is properly cited and the use is non-commercial. See: http:// creativecommons.org/licenses/by-nc/4.0/

(C) Article author(s) (or their employer(s) unless otherwise stated in the text of the article) 2018. All rights reserved. No commercial use is permitted unless otherwise expressly granted.

- Additional material is published online only. To view please visit the journal online (http://dx.doi.org/ 10.1136/bjsports-2017-098817).

\section{D) Check for updates}

To cite Taberner M, Cohen DD. Br J Sports Med 2018;52:1275-1278.

\section{Accepted 8 April 2018}

Published Online First 3 May 2018

Br J Sports Med 2018:52:1275-1278.

doi:10.1136/bjsports-2017-098817

\section{REFERENCES}

1 Askling CM, Malliaropoulos N, Karlsson J. High-speed running type or stretching-type of hamstring injuries makes a difference to treatment and prognosis. $\mathrm{Br} J$ Sports Med 2012:46:86-7.

2 Woods C, Hawkins RD, Maltby S, et al. The Football Association Medical Research Programme: an audit of injuries in professional football-analysis of hamstring injuries. Br J Sports Med 2004;38:36-41.
3 Brukner P, Connell D. 'Serious thigh muscle strains': beware the intramuscular tendon which plays an important role in difficult hamstring and quadriceps muscle strains. Br J Sports Med 2016;50:205-8.

4 van der Made AD, Almusa E, Whiteley R, et al. Intramuscular tendon involvement on MRI has limited value for predicting time to return to play following acute hamstring injury. Br J Sports Med 2018;52:83-8.

5 McCall A, Nedelec M, Carling C, et al. Reliability and sensitivity of a simple isometric posterior lower limb muscle test in professional football players. J Sports Sci 2015:33:1298-304.

6 De Vos RJ, Reurink G, Goudswaard GJ, et al. Clinical findings just after return to play predict hamstring re-injury, but baseline MRI findings do not. Br J Sports Med 2014;48:1377-84.

7 Timmins RG, Bourne MN, Shield AJ, et al. Short biceps femoris fascicles and eccentric knee flexor weakness increase the risk of hamstring injury in elite football (soccer): a prospective cohort study. Br J Sports Med 2016:50:1524-35.

8 Duhig S, Shield AJ, Opar D, et al. Effect of high-speed running on hamstring strain injury risk. Br J Sports Med 2016;50:1536-40.

9 Malone S, Roe M, Doran DA, et al. High chronic training loads and exposure to bouts of maximal velocity running reduce injury risk in elite Gaelic football. J Sci Med Sport 2017;20:250-4.

10 McCall A, Lewin C, O'Driscoll G, et al. Return to play: the challenge of balancing research and practice. $\mathrm{Br} J$ Sports Med 2017;51:702-3. 